\title{
Navigating the "liberation procedure": a qualitative study of motivating and hesitating factors among people with multiple sclerosis
}

This article was published in the following Dove Press journal:

Patient Preference and Adherence

10 September 2014

Number of times this article has been viewed

\section{Michelle Ploughman' \\ Chelsea Harris' \\ Stephen H Hogan' \\ Cynthia Murray ${ }^{2}$ \\ Michelle Murdoch ${ }^{3}$ \\ Mark W Austin' \\ Mark Stefanelli ${ }^{4}$}

'Recovery and Performance Laboratory, Faculty of Medicine, ${ }^{2}$ School of Nursing, Memorial University, ${ }^{3}$ Coalition of Persons with Disabilities, ${ }^{4}$ Department of Neurology, Faculty of Medicine, Memorial University, St John's, NL, Canada
Correspondence: Michelle Ploughman Recovery and Performance Laboratory, Faculty of Medicine, Memorial University, 4th floor, LA Miller Centre, 100 Forest Road, St John's, NL AIA IE5, Canada Tel +l 7097772099

Emailmploughm@mun.ca
Background: The debate within the multiple sclerosis (MS) community initiated by the chronic cerebrospinal venous insufficiency (CCSVI) hypothesis and the subsequent liberation procedure placed some people with MS at odds with health care professionals and researchers.

Objective: This study explored decision making regarding the controversial liberation procedure among people with MS.

Subjects and methods: Fifteen people with MS (procedure, n=7; no procedure, $n=8$ ) participated in audiotaped semistructured interviews exploring their thoughts and experiences related to the liberation procedure. Data were transcribed and analyzed using an iterative, consensus-based, thematic content-analysis approach.

Results: Participants described an imbalance of motivating factors affirming the procedure compared to hesitating factors that provoked the participant to pause or reconsider when deciding to undergo the procedure. Collegial conversational relationships with trusted sources (eg, MS nurse, neurologist) and ability to critically analyze the CCSVI hypothesis were key hesitating factors. Fundraising, family enthusiasm, and the ease of navigation provided by medical tourism companies helped eliminate barriers to the procedure.

Conclusion: Knowledge of factors that helped to popularize the liberation procedure in Canada may inform shared decision making concerning this and future controversies in MS.

Keywords: alternative medicine, CCSVI, decision making, liberation, multiple sclerosis, qualitative

\section{Introduction}

Although the exact etiology of multiple sclerosis (MS) is unknown, MS is believed to be an autoimmune disorder caused by a combination of genetic predisposition and environmental exposures. ${ }^{1}$ In contrast to the majority of research in MS, the recent hypothesis of chronic cerebrospinal venous insufficiency (CCSVI) proposed that anomalous venous blood flow from the brain and spinal cord created iron deposition leading to MS-related neuropathology. ${ }^{2}$ The CCSVI condition could then be treated using endovascular venoplasty to open obstructed areas of the jugular and azygous veins, coined the "liberation procedure". ${ }^{3}$ Results of randomized controlled trials of the liberation procedure have yet to be reported, and it is likely that its long-term efficacy and safety will only be assured after several years of observation. Recent studies suggest that CCSVI may not be a plausible explanation of MS pathology, ${ }^{4}$ and that the liberation procedure provides only temporary relief of subjective symptoms. ${ }^{5}$

The debate in the MS community initiated by the liberation procedure has been unprecedented. ${ }^{6}$ Many people with MS, upon hearing of the initial surgical results and 
anecdotal evidence, have strongly endorsed the procedure, often placing them at odds with health care providers and researchers. ${ }^{7}$ While researchers and neurologists maintain the need for stronger evidence of CCSVI, people with MS, particularly in Canada, have demanded access to the liberation procedure. ${ }^{8,9}$ Many people have traveled abroad at great personal cost to undergo this invasive procedure, bypassing health care professionals who may be in the "cross fire" of this debate. ${ }^{8}$

Despite a lengthy chronology of controversial MS therapies, ${ }^{10}$ there is little evidence describing factors that influence the patient's decision to undergo unproven procedures or the role of health professionals in that decision making. Although complementary and alternative medicine (CAM) treatments are common in $\mathrm{MS}^{11-13}$ and some have been proven safe and effective, ${ }^{14} \mathrm{CAM}$ decision making may not be comparable to decision making on the liberation procedure, since the procedure is different from typical CAM in that it is an invasive surgical intervention. The experience of the liberation procedure, particularly in Canada, ${ }^{8}$ where the patient, political, and media influences have been strong, provides an opportunity to explore patient autonomy as a key ingredient in informed health choices in MS. ${ }^{15}$

Literature regarding health-related decision making in other health conditions (breast cancer, cardiovascular disease, addictions) suggests that a participative consultation-style interaction between patient and doctor is essential to positive shared decision outcomes. ${ }^{16,17}$ This study aims to investigate the decision-making process from the patient's perspective to identify how health care professionals can better help their patients when faced with new and controversial treatment options. A thematic content-research approach using semistructured interviews was selected to best gain in-depth insight into the motivating and hesitating factors surrounding liberationprocedure decision making among patients with MS.

\section{Subjects and methods Participants}

Prior to commencing this qualitative study, ethical approval was granted by the Human Research Ethics Authority at Memorial University. We recruited potential participants from the local MS-specialty neurology clinic and the outpatient-rehabilitation service in Newfoundland, Canada. Initial contact was made by the potential participant's health care professional to determine interest in the study. Once a participant confirmed they were interested, a member of the research team telephoned the participant, confirmed inclusion criteria, obtained verbal consent, and scheduled the interview. In order to gather data based on current perceptions rather than from memory, participants were included if they had decided against the liberation procedure or had undergone the procedure within the previous 6 weeks. Participants were included if they were either available by telephone or lived within 90 minutes' traveling distance from the study site. The number of study participants was determined based on data saturation; the point at which no new information was obtained. The recruitment of participants ceased when there was approximately the same number of participants who had and had not had the liberation procedure and when there was a repetition of themes in the data.

\section{Interviews}

Interviews took place between May 2011 and April 2012, and were conducted by researchers who were outside the participant's circle of health care providers. Following written informed consent, we collected demographic information related to age, sex, education level, years with MS, type of MS, mobility, use of disease-modifying therapies, physical activity (minutes per week), and if applicable the date and location of the liberation procedure. Open-ended semistructured interviews (60-90 minutes) began with broad questions (Table 1), followed by more targeted probing queries to ascertain the participant's thoughts and feelings when considering their liberation procedure experience. Interviews were audiotaped and supplemented by detailed field notes taken by the second interviewer.

\section{Analysis}

Interview audio files were transcribed verbatim, errors corrected, field notes integrated, and identifiers, such as doctors' names, removed. Pseudonyms were created to protect participants' identity and maintain anonymity. The primary and second interviewers reread the interview documents, ensuring completeness and representativeness. We used an iterative, consensus-based, thematic content-analysis approach to analyze the data. ${ }^{18}$ Transcripts were thoroughly reviewed and open-coded independently by three investigators (CM, MM, MP), who each developed a provisional coding scheme, including themes and subthemes, that reflected key points in the transcripts. The investigators then collaboratively defined ambiguous codes and collapsed redundant codes until a consensus was reached on a coding scheme. One member of the research team $(\mathrm{CH})$ entered the data into the qualitative software program NVivo 10 (QSR International, Melbourne, Australia) to organize the data. The frequency of each code across all transcripts was examined to help detect patterns in the 
Table I Interview guide

Could you please tell me about your experience with MS?

How did you find out about the liberation (Zamboni) procedure?

How did you decide to have/not have this procedure?

What do you think about the procedure? How does it help people with MS?

(If underwent procedure): Tell us about how you arranged the procedure. What steps did you take? What was going through your mind?

(If underwent procedure): How do you think it has affected you or will affect you?

Who have you told about your decision to have/not have the procedure? How did they react?

What advice have you received from your health care providers about the procedure? How did you respond to that advice?

If you were to give advice to someone with MS about this procedure, what would you say?

What is your impression of how health providers and researchers feel about the procedure? What do you think health care providers

and researchers are doing, or should be doing?

How was the procedure portrayed in the media? How did that make you feel?

Do you have any other thoughts about this procedure?

Abbreviation: MS, multiple sclerosis.

data and guide the strength of subthemes. ${ }^{19}$ The final subthemes were then divided into external factors (finances, social support, etc) and internal factors (disease progression, level of disability, etc) that influenced each participant's decision on whether or not they had undergone the liberation procedure. This report focuses on the external factors, while internal factors influencing decision making have been published elsewhere. ${ }^{20}$

\section{Results}

\section{Participants}

Repetition of themes began following the 12th interview; however, we recruited four more participants to obtain an even representation of people who had undergone the procedure and those who had not. One participant withdrew between initial consent and the interview after discovering a procedure-related complication, leaving 15 participants (procedure, $n=7$; no procedure, $n=8$ ). Except for one telephone interview, all interviews took place in participants' homes. Participants who decided against the procedure were more often university educated, older, and less disabled than those who had undergone the procedure. Participant characteristics are described in Table 2.

\section{Themes}

External influencing factors - those factors that were outside of individuals' personal experience of MS - were divided into factors that supported the decision to undergo the liberation procedure (motivating factors) and those that provoked the

Table 2 Participant characteristics

\begin{tabular}{|c|c|c|}
\hline Characteristics (self-reported) & Procedure $($ mean \pm SD) & No procedure (mean \pm SD) \\
\hline \multirow[t]{2}{*}{ Sex } & Male: 3 & Male: 2 \\
\hline & Female: 4 & Female: 6 \\
\hline Age, years & $4 \mathrm{I} \pm 9.5$ & $53 \pm 8.7$ \\
\hline \multirow[t]{3}{*}{ Education } & High school: 2 & High school: I \\
\hline & Some postsecondary: 4 & Some postsecondary: 3 \\
\hline & University degree: I & University degree: 4 \\
\hline \multirow[t]{4}{*}{ MS type } & RRMS: 4 & RRMS: 2 \\
\hline & PPMS: I & PPMS: I \\
\hline & SPMS: I & SPMS: I \\
\hline & Unknown: I & Unknown: 4 \\
\hline Years with MS & $12 \pm 9.25$ & $14 \pm|1|$. \\
\hline \multirow[t]{4}{*}{ Mobility } & Independent: I & Independent: 6 \\
\hline & Uses a cane: I & Uses a cane: I \\
\hline & Uses walker or wheelchair: 4 & Uses walker or wheelchair: I \\
\hline & Uses a power wheelchair: I & Uses a power wheelchair: 0 \\
\hline \multirow[t]{5}{*}{ Procedure location } & USA: 3 & NA \\
\hline & Costa Rica: 3 & \\
\hline & Poland: 3 & \\
\hline & (Two participants received & \\
\hline & the procedure twice) & \\
\hline
\end{tabular}

Abbreviations: SD, standard deviation; MS, multiple sclerosis; RRMS, relapsing-remitting MS; PPMS, primary progressive MS; SPMS, secondary progressive MS; NA, not applicable. 
participant to pause or hesitate when deciding to undergo the procedure (hesitating factors; Figure 1). Our analysis revealed a relative imbalance of factors in favor of those that motivated participants to choose to undergo the procedure.

\section{Motivating factors}

The community "rallied around me"

Seven participants described finding themselves in the center of a swell of community enthusiasm. Paula, who had undergone the procedure, said, "... it was a hot topic ... there was a big buzz of excitement."

[People with MS are] bound by the community and everybody knows everybody, and so therefore everybody is willing to chip in and help. (Donna, no procedure)
Sharon described how she felt buoyed by the excitement of others. Phillip stated, "Everyone was telling me to get it done." When he returned from his surgery, he stated, "I was walking around without the cane, so people were just amazed." During Robert's interview, the local union leader visited to inquire about Robert's progress post-liberation and to deliver a donation.

Individuals and community groups became a powerful force in fundraising $(n=7)$ to support travel abroad to receive the liberation treatment. Ralph said that it was not unusual for someone to knock on his door and hand him "twenty or even a hundred dollars" after hearing about his story.

We raised ... [over \$20,000] in this little community that

I am from. (Sherry, procedure)

\section{Hesitating factors}

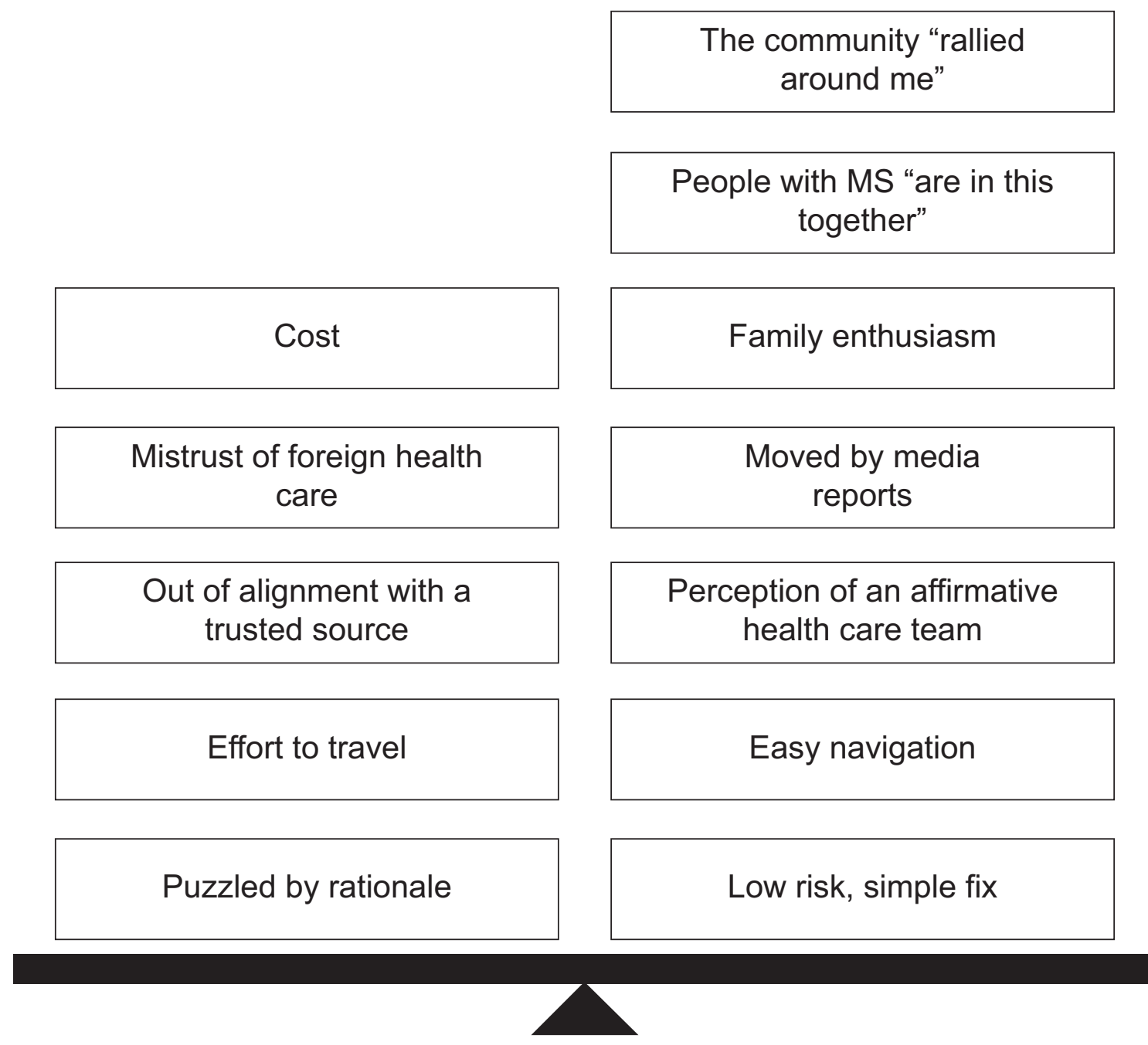

Figure I Influencing factors external to multiple sclerosis (MS) symptoms and disease severity could be divided into two categories: hesitating factors (five subthemes) and motivating factors (seven subthemes). 
However, two participants explained that after receiving the procedure, they felt obligated to demonstrate improvements. Sherry reported that there was "so much built on it", because people that were important to her had donated to "try and get me better". Although she was "a bit disappointed in [her] results because they were short-lived", she did not want her friends and family to think that their financial contribution was a waste, because "it was community money they had spent". She felt she had "let everybody down", which motivated her to join extra exercise classes after the procedure in an attempt to maximize her improvements.

\section{People with MS "are in this together"}

Five participants (who had undergone the procedure) identified social media, blogs, and Internet sites as means to receive encouragement and compare their own situation to the situations of others with MS. Tina described how she felt disconnected from the lives of others who did not have MS. She believed that people without MS could not empathize with her MS symptoms. Anecdotal stories from Internet sites and Facebook groups became important sources of information to locate the best surgery hospitals, compare hotels, and to connect with taxi drivers and medical tourism companies. Social media also became a tool to stay connected with people the participants met while traveling abroad to receive the procedure. The MS liberation-support network expanded as participants who had undergone the procedure found themselves providing advice to strangers who telephoned them. Paula said that she felt a strong affinity to her new support network, stating, "we are in this together".

\section{Family enthusiasm}

Eleven participants reported that their decisions about the liberation procedure were strongly influenced by the opinions of family and friends. Jennifer felt that she was required to defend her position not to undergo the procedure against her family, who felt she had a responsibility to act on this potential cure:

They were talking about this cure and how people were able to walk... . Everyone was saying, "Well, you don't know. Why wouldn't you go and try and clear it now before you get affected?" (Jennifer, no procedure)

... I'll tell you the honest to God truth why I did it.

I did it to get people to shut up and leave me alone. (Sherry, procedure)

Among seven of the interviewees, their immediate family members took primary responsibility to organize the logistics and funding for the trip abroad. Matthew, who required personal care at home, recalled that his mother and his sister "planned the whole thing".

\section{Moved by media reports}

Most participants $(n=10)$ identified the Canadian television documentary $W 5,{ }^{21}$ which aired on November 21, 2009, as their first encounter with the concept of the CCSVI theory and the liberation procedure. Participants described being moved by subsequent local television, newspaper, and radio accounts. Sherry said, "It seemed they had the big cure", and as Paula heard more and more about the procedure, she said, “the more excited I got!" Even though she eventually decided against the procedure, Anne felt that since the $W 5$ program had always been a trusted source of information, this new information presented was also trustworthy. Most participants (both those who decided to undergo the procedure and those who did not) felt that the CCSVI theory made sense to them, and following the $W 5$ program they immediately wanted more information:

It seemed to me from what he [Dr Zamboni] was saying that he was having good results, so I was kind of intrigued by it. (Tina, no procedure)

Following the $W 5$ program, local radio, television, and newspapers featured people with MS who were either preparing to undergo the procedure or had already received it. Some participants who were considering the procedure felt that the situations described in local reports paralleled their own situations. The fact that the subjects of the stories were local people strengthened the validity of the reported results from their points of view. Matthew described how he was motivated by the story of a local man who was able to stand from his wheelchair, who he felt, "He's just like me!"

\section{Perception of an affirmative health care team}

Participants in the study visited the MS clinic at least yearly and some more often. Four participants stated that they did not discuss the procedure with anyone from their health care team. Six of the seven participants who had undergone the procedure reported that they received a neutral response from either their family physician or MS neurologist, while two perceived that the message they received from their family physician was clearly affirmative. None of the participants described interaction with researchers or scientists regarding the procedure. Phillip reported that his family doctor said, "You've got nothing to lose, go for it." When participants described their conversations with MS neurologists, family physicians, and 
MS nurses, they seemed to perceive the health professional's neutral response as actual support for the procedure:

[My family doctor] didn't mind me going. He was pretty much like, "You got to do what you got to do if you think it's going to help." He didn't say don't go. (Matthew, procedure)

My doctor did say to me, "You have time", but never did he say, "Don't go. Don't get it done." (Tina, no procedure)

Five participants recounted that they felt frustrated and confused about the information received by members of their health care team regarding the liberation procedure. Phillip said of his MS neurologist, "He was all ifs, ands, and buts" and "it's not definite". In several cases, participants seemed to be seeking a simple yes/no response from their health care provider. Kimberly said that she would prefer if the doctors were more "straight" with her, telling her, "... we think this and we think you should do this because these are the benefits". Instead, she found that the doctors were vague, and reported that her MS neurologist advised, "I guess this is the information. You decide."

\section{Easy navigation}

All of the participants who had undergone the liberation procedure initially contacted either the hospital that offered the procedure directly or a medical tourism company. They felt that the interaction with hospital or company staff by email or by phone was overwhelmingly helpful and positive, and as a result they found the process simple and efficient. Sharon reported that she would advise those who were considering the liberation procedure to make contact with the foreign hospital staff who would remove any obstacles, so they "won't have any worries".

When referring to her experience in Costa Rica, Sherry said, "I mean, it's one bundle. Everything is there." She described it as an "all-inclusive vacation". In fact, she described how her husband was offered and received discounted cosmetic surgery during the trip.

\section{Low risk, simple fix}

None of the participants who had undergone the procedure described concern about risks associated with the procedure. Most participants stated that they had "researched" the liberation procedure on the Internet before making their decisions. Several of the participants who had undergone the procedure explained that the venoplasty procedure was a simple fix to a "plumbing problem":
Well, if the veins are blocked and they release that, people are going to feel better. (Barbara, no procedure)

No one should have blockages. Even if you don't have MS, if you have a blockage, it should be taken care of. I think it's ludicrous that our health care system is not doing anything right now to prevent this. (Brittany, procedure)

\section{Hesitating factors \\ Cost}

Eight participants reported that financial constraints were a major barrier in the decision to have the procedure. Six of the eight participants who reported cost as their major initial hesitating factor were supported by community fundraisers, but two participants, Anne and Barbara, did not want to participate in fundraisers, and wished to keep their diagnoses private. Both stated that they would have had the procedure if it were not for "financial reasons":

I mean, one of the things is that I'm just not into this business of fundraising and whatnot ... I mean, if the government wants to send me and pay for the expenses, you know, I'm not against it as such. (William, no procedure)

\section{Mistrust of foreign health care}

For those who discussed pausing and deliberating about traveling abroad to undergo the procedure $(n=10)$, they compared their trust in the Canadian health care system to that of other countries. Participants felt that Canadian regulations and evidence-informed health care assured them security, and that submitting to a new procedure in a foreign country increased their health risk. Participants were also concerned about the qualifications of surgeons carrying out the procedure and the risk of insufficient or incorrect information due to a language barrier. Donna pointed out that she did not trust foreign surgeons, because "You really don't know what their educational level is compared to ours." Three of the eight participants who had not undergone the liberation procedure indicated, "If it was offered in Canada, I'd go for it." Having the procedure in Canada would mitigate the risk from their points of view, as well as reduce the cost and fear of traveling abroad:

There are risks to it, besides the fact of going to a foreign country and having someone do something to you that you don't really know... . In Canada and the USA, we don't try things unless it is tested and tested and tested! ... [Also, just] because something is approved in the USA doesn't mean Canada will take it. (Jennifer, no procedure) 


\section{Out of alignment with a trusted source}

Only four of the 15 participants described having multiple conversations regarding the liberation procedure with their family doctor, MS neurologist, and/or MS nurse in which they debated the procedure's pros and cons. Donna described a particularly strong trust in her MS nurse, with whom she regularly discussed new information over the telephone. All four decided against the procedure at least partly based on the information gleaned from those conversations:

I had a discussion with [neurologist's name] about it, and I think he heard my concerns and we kind of just talked about it. My neurologist said as soon as he knows if this works or not, he will let me know, and then I'll make a decision and that's it. (Tina, no procedure)

I mean, we speak about it and he's not convinced. ... He's got the information ... and I go by what he says. (William, no procedure)

Not all participants followed the advice of their health care providers. Two participants discussed undergoing the liberation procedure against the advice of their doctors:

... [my neurologist's] opinion was negative. Like, his jaw dropped when I said I was going. (Robert, procedure)

\section{Effort to travel}

Seven participants reported that traveling abroad was a disincentive when making decisions on the procedure. For those who had undergone the procedure, they had been able to ameliorate their concerns by contacting and receiving advice from others who had traveled abroad. They also were assisted with planning by the hospital or the medical tourism company. Two participants felt that because of MS-related disability, they were physically unable to travel out of country to receive the procedure:

... first of all, how would I get to Poland? Second of all, I don't know if I could physically make the trip. (Tina, no procedure)

Even if I have tons of money, the traveling would be really hard to do. (Anne, no procedure)

\section{Puzzled by rationale}

Seven participants (two of whom decided to have the procedure) questioned the rationale underpinning the theory of blocked veins and MS. They also reported that they doubted the apparent improvements seen in MS symptoms described by television, radio, and newspaper reports.
These participants also had some postsecondary education, and clearly articulated both sides of the issue during their interview:

I thought it was very interesting that $25 \%$ of people had blocked veins, even though they're not people with MS. So, you know, obviously the [liberation procedure] wasn't a cure. (Donna, no procedure)

Participants felt that some of the improvements attributed to the liberation procedure presented in television, radio, and newspaper reports could have been related to the variability of MS and even the placebo effect:

I think a lot of it's more of mentally you think it's helping you. You're not going to be in a wheelchair and have this done and then all of a sudden get up and walk. (Jennifer, no procedure)

\section{Interplay between motivating and hesitating factors}

During the analysis, motivating factors were more numerous and more frequently mentioned than hesitating factors, resulting in an imbalance favoring the motivating factors (Figure 1). For participant decision making, the absence of one or two balancing factors in the "hesitating factors" category strengthened the affirmative decision to undergo the procedure. Most often, the hesitating factors that were absent among people with MS who had undergone the procedure and present in those who had decided against it were 1) out of alignment with a trusted source, and 2) puzzled by rationale.

\section{Discussion}

The purpose of this study was to explore liberation-procedure decision making among patients with MS. To our knowledge, this is the first report to focus specifically on the motivating and hesitating factors that play a role in liberation-procedure decision making from the perspective of people with MS.

We found that hesitating factors that caused participants to pause or reconsider the procedure were outweighed by motivating factors. Two hesitating factors seemed to be key ingredients in shifting decisions against the procedure: 1) the engagement in collegial debate/discussion with a trusted source knowledgeable of MS, such as an MS neurologist or MS nurse, and 2) critical analysis of the CCSVI hypothesis and liberation-procedure rationale. Health care professionals may have an important role to play in the event of a new controversial therapy for MS or other chronic diseases. 
Most participants in our study valued the advice of health care professionals when considering the liberation procedure, but were also seeking more definitive opinions than they received. It was clear that not all participants were able to evaluate critically all aspects of the liberation procedure, and in some cases they underestimated the risks and overestimated the potential benefits.

Shared decision making has been described as an ideal model to navigate choices where the benefit of a particular treatment is uncertain. ${ }^{22}$ In our group, participants were more likely to undergo the liberation procedure when shared informative interaction did not take place or when their health care providers adopted a neutral stance toward the liberation procedure. In response, participants sought out other sources of health information through online groups, websites, and peers, in order to make their health decisions. According to one study, people with MS cite mass media, such as the Internet, as their first source of health information, but also most often cite their physician as being their most trusted source. ${ }^{23}$ Heesen et $\mathrm{al}^{15}$ acknowledged the importance of patient autonomy in making decisions about MS treatment. They suggested that although people with MS are often highly knowledgeable about their disease, most of the evidence regarding MS-related treatments is ambiguous, and requires both successful interaction with health care professionals and the ability to analyze evidence critically. ${ }^{15}$ In the absence of a trusted source of health information, the Internet can gain more credibility and momentum, ${ }^{24}$ which may promote the use of controversial and even harmful treatments. Our findings highlight the importance of referring patients to health providers who are knowledgeable enough to offer expert advice.

In terms of television, newspaper, and radio reports, our data suggested that the media's role was to initiate and perpetuate the CCSVI-hypothesis momentum. Although most participants cited the $W 5$ national television program as their first introduction to CCSVI theory, they described the coverage of others with MS in their local area and the comparison to their own situations as a major impetus to undergo the procedure. The message that people with MS received was that a cure had been found, and it was up to them to act on it. We noticed that for participants who seemed to have weaker analytical skills and poorer relationships with their health care teams, the media and Internet network became the trusted source that outweighed any advice provided by health professionals.

Factors that caused participants to pause and reconsider decisions were largely removed by motivating factors. Motivating factors hastened health decisions by removing navigational barriers, such as cost, travel, and logistics. Medical tourism companies, family enthusiasm, and community fundraising became part of what participants described as a swell of support that in some cases they felt was pressed upon them. Since the liberation procedure was purported as being a potential cure for $\mathrm{MS},{ }^{9}$ families and communities took a proactive approach in helping participants undergo the procedure. In many cases, the procedure would not have happened without their influence. Most participants did not consider it as invasive or risky, even though the liberation procedure has several associated risks and in some cases has led to death. ${ }^{4}$

There are several limitations to the findings of this study. We recruited the sample of people in one province in Canada, perhaps limiting the applicability to other patients with MS and their health care teams. Furthermore, we interviewed participants at one point in time during the height of the liberation controversy. Their opinions and satisfaction with their decision could have changed over time. Although we know that participants visited the MS clinic at least yearly, we do not know the effect of frequency of health care visits on decision making. During the interviews, as the researchers, we endeavored to remain neutral on this controversial topic; however, we cannot assure with certainty that we were perceived that way or that we did not influence the data.

\section{Conclusion}

Our findings show that during the height of CCSVI and liberation-procedure interest, participants were influenced by motivating factors (ease of navigation, family and friends, media) that outweighed hesitating factors (cost, mistrust of foreign health care, advice from health professionals).

Two key hesitating factors that caused participants to doubt or reconsider the procedure included engagement in interactive discussion with a trusted health professional and the ability to analyze critically the CCSVI theory. We used in-depth interviews to gain insight into patient decision making that highlights the need for more research into patient-health care professional relationships and techniques to help patients critically evaluate emerging treatments. It is likely that patients with MS and other incurable chronic conditions will continue to contemplate unregulated procedures and medical tourism, and thus our research helps to identify areas for improvement in future MS care.

\section{Disclosure}

The authors report no conflicts of interest in this work. 


\section{References}

1. Ramagopalan SV, Dobson R, Meier UC, Giovannoni G. Multiple sclerosis: risk factors, prodromes, and potential causal pathways. Lancet Neurol. 2010;9(7):727-739.

2. Singh AV, Zamboni P. Anomalous venous blood flow and iron deposition in multiple sclerosis. J Cereb Blood Flow Metab. 2009; 29(12):1867-1878.

3. Zamboni P, Galeotti R, Menegatti E, et al. A prospective open-label study of endovascular treatment of chronic cerebrospinal venous insufficiency. J Vasc Surg. 2009;50(6):1348-1358.e1-e3.

4. Valdueza JM, Doepp F, Schreiber SJ, et al. What went wrong? The flawed concept of cerebrospinal venous insufficiency. J Cereb Blood Flow Metab. 2013;33(5):657-668.

5. Pryse-Phillips W, Stefanelli M, Murphy-Peddle K, Barrett B. An observational study of venoplasty in patients with multiple sclerosis. Can J Neurol Sci. 2013;40(2):203-209.

6. Ghezzi A. Funding CCSVI research is/was a waste of valuable time, money and intellectual energy: yes. Mult Scler. 2013;19(7):855-857.

7. Stanbrook MB, Hébert PC. Access to treatment for multiple sclerosis must be based on science, not hope. CMAJ. 2010;182(11):1151.

8. Chafe R, Born KB, Slutsky AS, Laupacis A. The rise of people power. Nature. 2011;472(7344):410-411.

9. Pullman D, Zarzeczny A, Picard A. "Media, politics and science policy: MS and evidence from the CCSVI Trenches". BMC Med Ethics. 2013;14:6

10. Wesselius T, Heersema DJ, Mostert JP, et al. A randomized crossover study of bee sting therapy for multiple sclerosis. Neurology. 2005; 65(11):1764-1768.

11. Yadav V, Bourdette D. Complementary and alternative medicine: is there a role in multiple sclerosis? Curr Neurol Neurosci Rep. 2006; 6(3):259-267.

12. Apel A, Greim B, Zettl UK. Complementary and alternative medicine and coping in neuroimmunological diseases. J Neurol. 2007;254 Suppl 2:II112-II115.
13. Marrie RA, Hadjimichael O, Vollmer T. Predictors of alternative medicine use by multiple sclerosis patients. Mult Scler. 2003;9(5): 461-466.

14. Bowling AC. Complementary and alternative medicine and multiple sclerosis. Neurol Clin. 2011;29(2):465-480.

15. Heesen C, Köpke S, Solari A, Geiger F, Kasper J. Patient autonomy in multiple sclerosis - possible goals and assessment strategies. J Neurol Sci. 2013;331(1-2):2-9.

16. Joosten E, de Weert G, Sensky T, van der Staak C, de Jong C. Effect of shared decision-making on therapeutic alliance in addiction health care. Patient Prefer Adherence. 2008;2:277-285.

17. Coulter A, Entwistle V, Gilbert D. Sharing decisions with patients: is the information good enough? BMJ. 1999;318(7179):318-322.

18. Green J, Thorogood N. Qualitative Methods for Health Research. 2nd ed. London: Sage; 2009.

19. Morgan DL. Qualitative content analysis: a guide to paths not taken. Qual Health Res. 1993;3(1):112-121.

20. Murray C, Ploughman M, Harris C, Hogan S, Murdoch M, Stefanelli M. The liberation procedure decision making experience for people with multiple sclerosis. Glob Qual Nurs Res. In press 2014.

21. Favaro A, St Philip E. The liberation treatment: a whole new approach to MS. 2009. Available from: http://www.ctvnews.ca/the-liberationtreatment-a-whole-new-approach-to-ms-1.456617. Accessed April 3, 2013.

22. Charles C, Gafni A, Whelan T. Shared decision-making in the medical encounter: what does it mean? (or it takes at least two to tango). Soc Sci Med. 1997;44(5):681-692.

23. Marrie RA, Salter AR, Tyry T, Fox RJ, Cutter GR. Preferred sources of health information in persons with multiple sclerosis: degree of trust and information sought. J Med Internet Res. 2013;15(4):e67.

24. Ziebland S, Chapple A, Dumelow C, Evans J, Prinjha S, Rozmovits L. How the internet affects patients' experience of cancer: a qualitative study. BMJ. 2004;328(7439):564.
Patient Preference and Adherence

\section{Publish your work in this journal}

Patient Preference and Adherence is an international, peer-reviewed, open access journal that focuses on the growing importance of patient preference and adherence throughout the therapeutic continuum. Patient satisfaction, acceptability, quality of life, compliance, persistence and their role in developing new therapeutic modalities and compounds to optimize

\section{Dovepress}

clinical outcomes for existing disease states are major areas of interest for the journal. This journal has been accepted for indexing on PubMed Central. The manuscript management system is completely online and includes a very quick and fair peer-review system, which is all easy to use. Visit http://www. dovepress.com/testimonials.php to read real quotes from published authors. 